\title{
HIV-Lipodystrophy more Prevalent in Women than Men in Tamil Nadu, India
}

Saramma Mini Jacob*, Annie Phoebe Kalyanasundaram, Elango Ramesh Kumar, Anitha Durairaj, Hemalatha Ramachandran and Sivakumar MR Department of Experimental Medicine, The Tamilnadu Dr MGR Medical University, Chennai, Tamilnadu, INDIA

\begin{abstract}
Background: As antiretroviral therapy (ART) becomes more available to the HIV infected population in rural areas in India, it is important to determine the prevalence of its long term complications. Therefore, it was proposed to find out the prevalence of lipodystrophy in patients receiving ART and compare the gender differences.

Material and methods: In this cross sectional study, consenting HIV-infected patients on ART visiting Namakkal District Head Quarters Hospital, Tamil Nadu, India, were recruited. They were on generic first-line fixed dose combinations of ART. Sociodemographics, anthropometric measurements, ART regimens and duration of treatment were recorded. Patients' self-perception of lipodystrophy was obtained using standardized questionnaires and clinically confirmed by the physician. An overnight fasting blood was drawn to determine serum lipids levels. Statistical analysis included Chi-square test, student t-test and Mann Whitney $U$ test.
\end{abstract}

Results: There were 145 HIV-infected subjects (46.9\% males, 53.1\% females) receiving ART for a mean 29.4 months. Mean age of the males were $38.18 \pm 8.85$ and for the females, it was $33.34 \pm 6.20$. The mean body mass index (BMI) for the males was $21.95 \pm 3.94 \mathrm{~kg} / \mathrm{m}^{2}$ while for the females it was $21.14 \pm 3.54 \mathrm{~kg} / \mathrm{m}^{2}$. The overall prevalence of lipodystrophy was $60.69 \% ; 22.72 \%$ with lipohypertrophy, $51.14 \%$ with lipoatrophy, and $22.72 \%$ with mixed pattern. Women had a higher prevalence of lipodystrophy than men $(p=0.004)$. Lipoatrophy was higher in females $(p=0.015)$ and mixed pattern $(p=0.015)$. There was a higher prevalence of facial atrophy, fat loss in arms, fat loss in legs and fat loss in buttocks among women compared to men. Women with lipodystrophy had higher BMI, CD4 counts, VLDL cholesterol and triglycerides.

Conclusion: Women had significantly higher rates of generalized lipodystrophy and particularly lipoatrophy when compared with men taking first-line antiretroviral regimen. Compared with women without lipodystrophy, those with lipodystrophy had lipid abnormalities.

Keywords: Lipodystrophy, Lipoatrophy, Namakkal, India

\section{Introduction}

According to India's National AIDS Control Organization (NACO), an estimated 2.4 million people in the country had HIV infection in 2009, 39\% of them are women [1]. As of December 2010, 384726 people living with HIV are on antiretroviral therapy in India and more than 47,955 of them are in Tamil Nadu [2], India's seventh most populous state. As ART becomes more available to the HIV infected population in Namakkal district of Tamilnadu, it is important to determine the prevalence of its long term complications. Lipodystrophy associated with long term ART has been increasingly recognized in India; lipoatrophy appears to be the predominant manifestation than lipohypertrophy [3]. Studies from the West states that women are at a higher risk of lipodystrophy than men (1.9 relative risk) [4]. Women are more likely to report fat accumulation in the abdomen and breasts and hypertriglyceridemia, whereas men are more likely to describe fat depletion from the face and extremities along with hypertension and hypercholesterolemia. Therefore, it was proposed to find out the prevalence of lipodystrophy in patients receiving ART and compare the gender differences.

\section{Materials and Methods}

\section{Study population}

In this cross sectional study, HIV-infected patients on ART, visiting the ART center at Namakkal District Head Quarters Hospital, Tamil Nadu, India, were recruited from January-April 2009. They were on generic first-line fixed dose combinations of ART (Ziduvudine/ Stavudine based regimens), provided for free by the Indian Government under its national ART program. All the subjects were aged 18 years or above. Written informed consent was obtained from all the participants. The exclusion criteria for all the subjects were active substance or alcohol abuse, current usage of anabolic steroids, glucocorticoids, lipidlowering or hypoglycemic drugs, recent opportunistic infection or malignancy.

\section{Assessments and measurements}

Sociodemographic information, anthropometric measurements and details of type and duration of ART regimen were recorded. Patients' self-perception of lipodystrophy (lipohypertrophy and lipoatrophy) was obtained using standardized questionnaires and clinically confirmed by the physician at the ART center. Lipoatrophy was defined as facial fat loss, peripheral fat loss on arms, legs or buttocks. Lipohypertrophy was defined as central fat gain on upper back, chest or abdomen. The questionnaire was administered in the local language (Tamil), which

*Corresponding authors: Saramma Mini Jacob, M.D., Department of Experimental Medicine, The Tamilnadu Dr MGR Medical University No.69, Anna Salai, Guindy, Chennai, Tamilnadu, India, E-mail: saramini@yahoo.com

Received January 25, 2012; Accepted March 05, 2012; Published March 05, 2012

Citation: Jacob SM, Kalyanasundaram AP, Ramesh Kumar E, Anitha D, Hemalatha R (2012) HIV-lipodystrophy more Prevalent in Women than Men in Tamil Nadu, India. J AIDS Clinic Res 3:143. doi:10.4172/2155-6113.1000143

Copyright: (c) 2012 Jacob SM, et al. This is an open-access article distributed under the terms of the Creative Commons Attribution License, which permits unrestricted use, distribution, and reproduction in any medium, provided the original author and source are credited. 
was spoken by all patients. The questionnaire was explained in detail to the patients to ensure all subjects understood the requirements.

Anthropometric measurements included body weight $(\mathrm{kg})$, height $(\mathrm{cm})$, waist circumference $(\mathrm{cm})$ and hip circumference $(\mathrm{cm})$. Subjects were weighed wearing light clothing and without shoes to the nearest 0.1 $\mathrm{kg}$. Height was measured to the nearest millimeter using a stadiometer. Body Mass Index (BMI, weight in kg divided by the square of the height in $\mathrm{m}$ ) was calculated. Waist circumference to the nearest millimeter was measured using a cloth tape measure halfway between the lowest rib and the iliac crest. Hip circumference to the nearest millimeter was measured at the level of the anterior superior iliac spine when this could be palpated; otherwise, it was measured at the broadest circumference below the waist. The waist-to-hip ratio (WHR) was calculated from these measures.

The CD4 counts before initiation of therapy was recorded for patients and on therapy current CD4 counts were recorded for all the HIV-infected patients. An overnight fasting blood was drawn to determine serum lipids levels. Aliquots of serum were stored at $-80^{\circ} \mathrm{C}$ until testing. Total cholesterol, high-density lipoprotein (HDL) cholesterol, and triglycerides were analyzed by colorimetric enzymatic methods with reagents purchased from Identii (Spain) using Stat Fax 3300 chemistry analyzer (Awareness Technology, USA). Low-density lipoprotein (LDL) cholesterol and Very-density lipoprotein (VLDL) was calculated using the Friedewald formula.

\section{Statistical analysis}

Data was collected on an individual case basis \& then translated to the SPSS version 10.0 statistics software, package for statistical analysis. Descriptive statistics were presented for all variables. Data were analyzed with the Chi-square test. Linear association between any two variables was studied using Pearson Correlation. Mean differences between the groups were analyzed by student $t$ test and Mann Whitney $\mathrm{U}$ test (non parametric). A significance level of $\mathrm{p}<0.05$ was used for all tests and comparisons.

\section{Results}

There were 145 HIV-infected subjects ( $46.9 \%$ males, $53.1 \%$ females) currently receiving ART for a mean 29.4 months (range, 2-60 months) (Table1). Fifty four (37.8\%) of them were on generic fixed combination of AZT (zidovudine)/3TC (lamivudine) and NVP (Nevirapine) regimen while $4(2.8 \%)$ were on AZT/3TC/EFV (efavirenz) regimen. Eighty three (58\%) subjects were on $\mathrm{d} 4 \mathrm{~T}$ (stavudine)/3TC/NVP combination while $2(1.4 \%)$ of them were on $\mathrm{d} 4 \mathrm{~T} / 3 \mathrm{TC} / \mathrm{EFV}$ regimen. Mean age of the males were $38.18 \pm 8.85$ and for the females, it was $33.34 \pm 6.20$. The mean body mass index for the males was $21.95 \pm 3.94 \mathrm{~kg} / \mathrm{m}^{2}$ while for the females it was $21.14 \pm 3.54 \mathrm{~kg} / \mathrm{m} 2$. The mean CD4 count of the subjects was $143.23 \mu \mathrm{l}$ at the initiation of antiretroviral therapy.

In this study the prevalence of self-perception of lipodystrophy was $60.7 \%$; with $23.53 \%$ lipohypertrophy, $52.94 \%$ lipoatrophy, and $23.53 \%$ mixed pattern.

\section{Comparison between men and women}

Women were younger than men with a higher percentage in the $24-35$ age range $(78.3 \%$ vs $21.7 \% ; \mathrm{p}=0.00)$. There was also a higher percentage of women with BMI lesser than $18.5 \mathrm{~kg} / \mathrm{m}^{2}$ compared to men $(76.2 \%$ vs $23.8 \%$; $\mathrm{p}=0.167)$. With regard to type of ART regimen, $53.40 \%$ of women and $46.60 \%$ of men were on zidovudine based regimen while $51.80 \%$ of women and $48.20 \%$ of men were on stavudine based regimens $(\mathrm{p}=0.488)$.
There was a significant difference in the self-perception of lipodystrophy pattern between males and females with females having a higher prevalence $(71.4 \%$ vs $48.5 \%$; $=0.004)$ (Table 2). Prevalence of lipoatrophy was also higher in females $(40.8 \%$ vs $21.2 \%$; $\mathrm{p}=0.015)$ as well as prevalence of mixed pattern $(17.1 \%$ vs $10.6 \%$; $=0.015)$. Moreover, there was a higher prevalence of facial atrophy among women compared to men ( $43.4 \%$ vs $22.3 \%$; $\mathrm{p}=0.029)$. Women also had a higher prevalence of fat loss in arms ( $34.2 \%$ vs $14.9 \%$; $\mathrm{p}=0.025)$, fat loss in legs (25\% vs $13.4 \%$; $=0.210)$, and fat loss in buttocks $(19.7 \%$ vs $4 \%$; $=0.051$ ). By univariate analysis, lipodystrophy was positively correlated with age $(\mathrm{r}=0.249 ; \mathrm{p}=0.029)$ and $\mathrm{CD} 4$ counts $(\mathrm{r}=0.448$; $\mathrm{p}=0.006$ ) in women, but not in men.

There were no significant differences between men and women with regard to mean CD4 counts and lipid profile values (Table 1).

\section{Comparison between women with and without lipodystrophy}

Women with lipodystrophy when compared to women without lipodystrophy had significantly higher mean BMI ( $p=0.003)$, mean CD4 count $(\mathrm{p}=0.006)$, mean VLDL cholesterol $(\mathrm{p}=0.046)$ and mean triglycerides $(\mathrm{p}=0.046)$ (Table 3$)$.

\section{Discussion}

In this study the overall prevalence of lipodystrophy among the study subjects was $60 \%$ with more than half the patients having lipoatrophy rather than lipohypertrophy and mixed pattern. Women had significantly higher rates of generalized lipodystrophy and particularly lipoatrophy when compared with men taking first-line antiretroviral regimen at Namakkal Government Hospital in Tamil $\mathrm{Nadu}$ India. Compared with women without lipodystrophy, those with

\begin{tabular}{|l|l|l|l|}
\hline Variable & Men $\mathrm{n}=68$ & Women $\mathrm{n}=77$ & P value \\
\hline Age $($ years $)$ & $38.18 \pm 8.85$ & $33.34 \pm 6.20$ & 0.00 \\
\hline Body mass index $\left(\mathrm{kg} / \mathrm{m}^{2}\right)$ & $21.95 \pm 3.94$ & $21.14 \pm 3.54$ & 0.202 \\
\hline Waist hip ratio & $0.94 \pm 0.09$ & $0.92 \pm 0.14$ & 0.404 \\
\hline ART duration $(\mathrm{months})$ & $28.67 \pm 11.82$ & $30.12 \pm 13.79$ & 0.506 \\
\hline CD4 cell count $\left(\mathrm{cells} / \mathrm{mm}^{3}\right)$ & $140.03 \pm 128.28$ & $146.12 \pm 113.07$ & 0.766 \\
\hline Total Cholesterol $(\mathrm{mg} / \mathrm{dl})$ & $203.43 \pm 63.43$ & $210.74 \pm 104.74$ & 0.618 \\
\hline HDL-Cholesterol $(\mathrm{mg} / \mathrm{dl})$ & $49.46 \pm 16.41$ & $55.45 \pm 19.59$ & 0.048 \\
\hline LDL-Cholesterol $(\mathrm{mg} / \mathrm{dl})$ & $118.31 \pm 43.65$ & $118.06 \pm 99.79$ & 0.985 \\
\hline VLDL-Cholesterol $(\mathrm{mg} / \mathrm{dl})$ & $36.39 \pm 40.0$ & $37.62 \pm 48.32$ & 0.865 \\
\hline Triglycerides $(\mathrm{mg} / \mathrm{dl})$ & $181.93 \pm 199.78$ & $188.07 \pm 241.58$ & 0.865 \\
\hline
\end{tabular}

Table 1: Characteristics of participants

†t-test

Mean values with standard deviations are given

\begin{tabular}{|l|l|l|l|}
\hline & Men $(\mathrm{n}=68) \mathrm{n}(\%)$ & Women $(\mathrm{n}=77) \mathrm{n}(\%)$ & P value \\
\hline Lipodystrophy & $33(48.5)$ & $55(71.4)$ & 0.004 \\
\hline Lipoatrophy & $14(21.2)$ & $31(40.8)$ & 0.015 \\
\hline Mixed pattern & $7(10.6)$ & $13(17.1)$ & 0.015 \\
\hline Lipohypertrophy & $10(15.2)$ & $10(13.2)$ & 0.015 \\
\hline Facial Atrophy & $15(22.37$ & $33(43.4)$ & 0.029 \\
\hline Fat loss in arms & $10(14.9)$ & $26(34.2)$ & 0.025 \\
\hline Fat loss in legs & $9(13.4)$ & $19(25)$ & 0.210 \\
\hline Fat loss in buttocks & $5(7.4)$ & $15(19.7)$ & 0.051 \\
\hline Fat gain in upper back & $2(3.0)$ & $8(10.5)$ & 0.125 \\
\hline Fat gain in chest & $3(4.5)$ & $5(6.6)$ & 0.432 \\
\hline Fat gain in abdomen & $13(19.7)$ & $19(25)$ & 0.553 \\
\hline
\end{tabular}

Table 2: Lipodystrophy pattern among men and women †Pearson Chi-square. 


\begin{tabular}{|l|l|l|l|}
\hline Variable & $\begin{array}{l}\text { Women with Lipo- } \\
\text { dystrophy }(\mathrm{n}=54)\end{array}$ & $\begin{array}{l}\text { Women without Li- } \\
\text { podystrophy }(\mathrm{n}=22)\end{array}$ & P Value† \\
\hline Age $($ years $)$ & $34.4 \pm 6.1$ & $30.9 \pm 5.9$ & 0.024 \\
\hline Body mass index $\left(\mathrm{kg} / \mathrm{m}^{2}\right)$ & $21.5 \pm 3.9$ & $20.3 \pm 1.9$ & 0.003 \\
\hline CD4 cell count $\left(\mathrm{cells} / \mathrm{mm}^{3}\right)$ & $660.2 \pm 268.9$ & $366.6 \pm 116.9$ & 0.006 \\
\hline Total Cholesterol $(\mathrm{mg} / \mathrm{dl})$ & $216.8 \pm 118.8$ & $195.6 \pm 55.6$ & 0.285 \\
\hline HDL-Cholesterol $(\mathrm{mg} / \mathrm{dl})$ & $54.9 \pm 19.6$ & $56.8 \pm 19.9$ & 0.713 \\
\hline Total-C/HDL-C & $4.5 \pm 3.6$ & $3.9 \pm 2.4$ & 0.272 \\
\hline LDL-Cholesterol $(\mathrm{mg} / \mathrm{dl})$ & $119.6 \pm 113.8$ & $114.1 \pm 51.9$ & 0.387 \\
\hline VLDL-Cholesterol $(\mathrm{mg} / \mathrm{dl})$ & $42.7 \pm 56$ & $24.7 \pm 11.6$ & 0.046 \\
\hline Triglycerides $(\mathrm{mg} / \mathrm{dl})$ & $213.8 \pm 280.1$ & $123.8 \pm 58.1$ & 0.046 \\
\hline
\end{tabular}

Table 3: Comparison between women with and without lipodystrophy

t t-test

Mean values with standard deviations are given

lipodystrophy had significantly higher CD4 counts, very low-density lipoprotein (VLDL) cholesterol, and triglycerides.

In 1998, lipodystrophy was first described while using HAART [5,6]. Several studies have recorded higher rates of lipodystrophy in women than men, including, for example, reports from Benin [7], Canada [8] and Italy [9]. Yet lipodystrophy rates clearly depend on an array of study factors, including whether the study is prospective or cross-sectional, how lipodystrophy is defined, whether objective measures are used, and the statistical methods applied. A prospective study of 245 women and 723 men in Quebec, for example, found no gender differences in the overall incidence of treatment-limiting lipodystrophy, even after statistical adjustment for age, CD4 count, viral load, time since HIV diagnosis, history of AIDS-defining illness, and year of antiretroviral initiation [10]. A recent study of 2,072 patients from 12 clinics in 12 Asian countries (including India) observed $10.5 \%$ of patients having lipodystrophy [11]. The study also found that there was an increased risk of lipodystrophy for those on ART for a longer period of time. A study from YRG care from India concluded that lipoatrophy is a predominant presentation of HIV associated lipodystrophy; however majority of the presentations was observed in males [3]. While a recent study of 32 patients on ART in South India noticed that $28 \%$ of men and $75 \%$ of women reported a change in fat distribution. Metabolic changes with increased abdominal fat and loss of peripheral subcutaneous fat especially in the face and upper limbs was more prominent in women than in men [12]. While our study findings were similar to the above observations in women with lipodystrophy, $41 \%$ of them had lipoatrophy with higher prevalence of facial atrophy, fat loss in arms, legs and buttocks. Lipodystrpohy positively correlated with age in women but not in men.

Stavudine based regimens were most commonly used because of its low cost. Next to lamivudine, stavudine was the most commonly used NRTI, because of its relatively low cost [13]. Stavudine is most often associated with mitochondrial toxicity, which results in high rates of lipoatrophy, peripheral neuropathy, lactic acidosis, and pancreatitis [14]. Studies showed a higher prevalence on lipoatrophy among patients who were on Stavudine based regimens than Zidovudine even in our population [15]. This had prompted the World Health Organization to change their antiretroviral therapy policy (2006) to use ziduvudine rather than stavudine. However in this study, there was no significant increase in lipoatrophy in patients receiving stavudine based regimen than zidovudine based regimens. This is contrary to other studies from India. This may be due to the small sample size in this study.

Several different techniques are available to assess fat distribution and body composition in HIV positive patients, such as DEXA, BIA, computed tomography and the use of radio-labeled water [12].
Composition changes are different in men and women on generic combinations. Guaraldi $\mathrm{G}$ et al. from Italy evaluated the estimate of body size perception in HIV-infected women with lipodystrophy and concluded that self estimate of body size is accurate in HIV-infected women and self-assessment of physical features of lipodystrophy is reliable [16].

The presence of lipodystrophy among women was associated with lipid abnormalities. In our study women with lipodystrophy had significant higher mean BMI, mean CD4 counts, VLDL cholesterol and mean triglycerides than among HIV infected women without lipodystrophy. Previous studies have identified hypertriglyceridemia in HIV-infected patients, which results from increased production and decreased clearance of very low-density lipoprotein by the liver [17].

In clinical practice patients are advised to notify their doctor if they find any changes in their appearance. In resource limited settings as ours, no interventions are implemented. However studies have shown withdrawal of thymidine analogues may reverse lipoatrophy $[18,19]$ and especially the use of Stavudine [15]. In 2010 the national program has decided to phase out the use of Stavudine in the first line of Antiretroviral Therapy by the year 2013.

Limitation of our study include cross sectional study, small sample size, the absence of baseline BMI, severity of lipoatrophy and specific techniques were not used to assess the fat distribution and body composition objectively. Therefore in future, longitudinal studies need to be done to assess the relationship of lipodystrophy with other metabolic abnormalities such as diabetes mellitus and cardiovascular diseases is this setting.

\section{Conclusion}

In this study women had a significantly higher prevalence of lipodystrophy and particularly lipoatrophy than males. The presence of lipodystrophy was associated with lipid abnormalities. This study highlights the need for careful clinical and laboratory monitoring of female patients with lipodystrophy during antiretroviral treatment.

\section{Acknowledgments}

The authors are grateful to the study participants. The authors thank all the staff at the ART center and at the PPTCT center of the Namakkal District Headquarter hospital.

\section{References}

1. http://www.nacoonline.org/Quick Links/HIV Data/

2. NACO Annual report 2010-2011: 62

3. Saghayam S, Chaguturu SK, Kumarasamy N, Solomon S, Mayer KH, et al. (2004) Lipoatrophy is the predominant presentation of HIV-associated lipodystrophy in Southern India. Clin Infect Dis 38: 1646-1647.

4. Sorli Redó ML, Knobel Freud H, Montero M, Jericó Alba C, Guelar Grimberg A, et al. (2007) Sex influence in lipodystrophy of HIV-infected patients and its association with cardiovascular risk factors. An Med Interna 24:168-172.

5. Carr A, Samaras K, Burton S, Law M, Freund J, et al. (1998) A syndrome of peripheral lipodystrophy, hyperlipidaemia and insulin resistance in patients receiving HIV protease inhibitors. AIDS 12: F51-58.

6. Brinkman K, Smeitink JA, Romijn JA, Reiss P (1999) Mitochondrial toxicity induced by nucleoside-analogue reverse-transcriptase inhibitors is a key facto in the pathogenesis of antiretroviral- therapy-related lipodystrophy. Lancet 354: $1112-1115$.

7. Zannou DM, Denoeud L, Lacombe K, Amoussou-Guenou D, Bashi J, et al. (2009) Incidence of lipodystrophy and metabolic disorders in patients starting non-nucleoside reverse transcriptase inhibitors in Benin. Antivir Ther 14: 371380. 
Citation: Jacob SM, Kalyanasundaram AP, Ramesh Kumar E, Anitha D, Hemalatha R (2012) HIV-lipodystrophy more Prevalent in Women than Men in Tamil Nadu, India. J AIDS Clinic Res 3:143. doi:10.4172/2155-6113.1000143

Page 4 of 4

8. Heath KV, Chan KJ, Singer J, O'Shaughnessy MV, Montaner JS, et al. (2002) Incidence of morphological and lipid abnormalities: gender and treatment differentials after initiation of first antiretroviral therapy. Int J Epidemiol 31 1016-1020.

9. Galli M, Veglia F, Angarano G, Santambrogio S, Meneghini E, et al. (2003) Gender differences in antiretroviral drug-related adipose tissue alterations. Women are at higher risk than men and develop particular lipodystrophy patterns. J Acquir Immune Defic Syndr 34: 58-61.

10. Boulassel MR, Morales R, Murphy T, Lalonde RG, Klein MB (2006) Gender and long-term metabolic toxicities from antiretroviral therapy in HIV-1 infected persons. J Med Virol 78: 1158-1163.

11. Han SH, Zhou J, Saghayam S, Vanar S, Phanuphak N, et al. (2011) Prevalence of and risk factors for lipodystrophy among HIV-infected patients receiving combined antiretroviral treatment in the Asia-Pacific region: Results from the TREAT Asia HIV Observational Database (TAHOD). Endocr J 58: 475-84.

12. Padmapriyadarsini C, Swaminathan S, Karthipriya MJ, Narendran G, Menon PA, et al. (2010) Morphologic and Body Composition Changes are Different in Men and Women on Generic Combination Antiretroviral Therapy- An Observational Study. J Assoc Physicians India 58: 375-377.

13. Subbaraman R, Chaguturu SK, Mayer KH, Flanigan T, Kumaraswamy N (2007)
Adverse Effects of Highly Active Antiretroviral Therapy in Developing Countries. Clin Infect Dis 45: 1093-1101.

14. McComsey G, Lonergan JT (2004) Mitochondrial dysfunction: patient monitoring and toxicity management. J Acquir Immune Defic Syndr 37: S30-35.

15. Nolan D, Mallal S (2004) The role of nucleoside reverse transcriptase inhibitors in the fat redistribution syndrome. J HIV Ther 9: 34-40.

16. Guaraldi G, Orlando G, Murri R, Orlandi E, Covezzi R, et al. (2001) Selfestimate questionnaires are reliable for lipodystrophy diagnosis. Antivir Ther 6: 48

17. Hellerstein MK, Grunfeld C, Wu K, Christiansen M, Kaempfer S, et al. (1993) Increased de novo hepatic lipogenesis in human immunodeficiency virus infection. J Clin Endocrinol Metab 76: 559-565.

18. Viganò A, Brambilla P, Cafarelli L, Giacomet V, Borgonovo S, et al. (2007) Normalization of fat accrual in lipoatrophic, HIV-infected children switched from stavudine to tenofovir and from protease inhibitor to efavirenz. Antivir Ther 12: 297-302.

19. Martínez E, García-Viejo MA, Blanco JL, Bianchi L, Buira E, et al. (2000) Impact of switching from human immunodeficiency virus type 1 protease inhibitors to efavirenz in successfully treated adults with lipodystrophy. Clin Infect Dis 31: 1266-1273. 